\title{
Aspectos da discussão hodierna internacional sobre a história e as origens dos contos de fadas literários: a autoria distribuída
}

Aspects of the current discussion about the history and the origins of literary fairy tales: distributed authorship

$\underline{\underline{\text { Andre Luiz Ming Garcia }}}$

1 Bacharel, licenciado, mestre e doutorando em Letras pela Universidade de São Paulo. 
RESUMO: A questão da autoria dos contos de fadas literários é complexa e a discussão acerca do tema dista da univocidade. Autores internacionais pouco explorados em artigos e trabalhos acadêmicos brasileiros sobre o tema, como Ruth Bottigheimer, Jack Zipes, Martus e Pabst, põem em xeque o senso comum de que a autoria dessas narrativas seria essencialmente a "voz do povo" e apontam para uma autoria coletiva e, como denomina Pabst, dispersa ou distribuída para essas narrativas. Com vistas a explorar essa abordagem, no presente artigo realizamos uma revisão bibliográfica crítica das contribuições de autores nacionais e estrangeiras a respeito das origens e da autoria dos contos de fadas.

PALAVRAS-CHAVE: contos de fadas; autoria dispersa; história dos contos de fadas

ABSTRACT: The issue of the authorship of literary fairy tales is complex and the discussion about the theme is far from settled. International authors not commonly explored in Brazilian articles and academic works on the subject, such as Ruth Bottigheimer, Jack Zipes, Martus and Pabst call into question the common sense that the authorship of these narratives represents essentially the "voice of the people" and point to a collective authorship which, as Pabst calls it, can be considered dispersed or distributed. In order to explore this approach, in this article we review critically the contributions of national and foreign authors regarding the origins and authorship of fairy tales.

KEYWORDS: fairy tales; distributed authorship; story of fairy tales 


\section{Introdução}

A temática dos contos de fadas costuma despertar intenso interesse por parte do público em geral e de estudiosos dos campos das Letras e da Educação, mais especificamente, apesar de um crescente interesse acerca do tema também estar se revelando entre estudiosos da Psicologia e da Psicanálise ${ }^{2}$. Tal fato é atestado pelo sucesso de público de cursos livres e de eventos acadêmicos que circunscrevem esse instigante e seminal gênero literário. As explicações para esse interesse são, potencialmente, muitas. Primeiramente, trata-se de obras extremamente populares, em parte graças às versões cinematográficas realizadas pelos Estúdios Disney na primeira metade do século passado, mas também ao fato de consistirem nas primeiras leituras de grande parte de nossas crianças, que com elas têm em contato em casa, por intermédio dos pais, ou na educação infantil institucional. Além disso, como atualmente se discute no âmbito da Psicologia, a influência dos contos de fadas se vê refletida nas concepções hodiernas de amor romântico e nos ideais de relacionamento amoroso monogâmico e eterno, com ambos os parceiros completando-se e complementando-se, desejavelmente, ao longo de uma vida ou por todo o sempre ${ }^{3}$.

Paradoxalmente, a pesquisa acadêmica brasileira sobre o conto de fadas, apesar de conter contribuições valiosas para os estudos do tema, pouco se conecta com a produção internacional desenvolvida sobretudo na Europa e na América do Norte, apresentando. por vezes, lacunas de informação que necessitam ser mitigadas mediante a realização de pesqui-

2 Essa asserção refere-se essencialmente à situação dos estudos sobre o conto de fadas no Brasil. $\mathrm{Na}$ Alemanha e no Reino Unido, entretanto, o conto de fadas encontra pouco espaço entre estudiosos da literatura e pesquisas a respeito do tema costumam ser prioritariamente conduzidas por folcloristas. 3 No âmbito da psicologia, trabalhos como Almeida (2013) abordam a influência dos príncipes e princesas de contos de fadas audiovisuais da Disney nas concepções contemporâneas de amor romântico e Damasceno (2008) discute a influência do conto de fadas nos ideais românticos e de casamento femininos. Para além disso, Schneider e Torossian (2009) discutem o papel dos contos de fadas na prática psicanalítica. Além disso, é bastante difundido em nosso meio acadêmico a obra de Bettelheim (1980) sobre a psicanálise dos contos de fadas. 
sas que integrem trabalhos publicados em diferentes línguas e países. Além disso, a produção nacional sobre o conto de fadas está concentrada na forma de livros e capítulos de livros, em vez de artigos científicos publicados em periódicos com revisão por pares, o que fragiliza o impacto dessas publicações no crescimento do estado da arte do tema.

Entre os autores estrangeiros comumente citados em trabalhos brasileiros a respeito do tema, encontram-se frequentemente Vladimir Propp, André Jolles, Max Lüthi e Bruno Bettelheim, responsáveis por trabalhos seminais acerca do assunto e que não podem ser negligenciados, mas que não representam mais o estado da arte atualizado das pesquisas neste campo, embora continuem sendo relevantes e seminais. $\mathrm{O}$ fato de os mesmos trabalhos serem repetidamente citados implica a sedimentação de alguns sensos comuns acadêmicos que estão sendo superados pela pesquisa internacional.

Um exemplo concreto desse problema é o tratamento dado à temática da autoria e das origens dos contos de fadas. $\mathrm{Na}$ bibliografia nacional sobre o tema, repete-se amiúde a noção de que os contos de fadas, denominados folclóricos ou populares por alguns dos autores supracitados, derivariam essencialmente da voz popular e, mais que isso, a representariam.

Iniciativas para atualizar essa visão ocorrem, por exemplo, com a recente criação de um subgrupo de estudos acerca da complexa temática da autoria dos contos de fadas literários no seio do grupo de pesquisa Produções Literárias e Culturais para Crianças e Jovens (USP/ $\mathrm{CNPq}$ ), liderado por Maria Zilda da Cunha. A criação desse grupo de estudos aponta para o reconhecimento da necessidade de investigar mais profundamente e atualizar as informações disponíveis no Brasil sobre esta temática complexa e que dista da simplicidade e da univocidade.

No presente artigo, pretende-se apresentar o pensamento de alguns autores estrangeiros selecionados que se debruçaram sobre a temática da origem e da história dos contos de fadas, propondo-nos instigantes questionamentos que visam a contribuir para as reflexões que temos empreendido no Brasil sobre este tema. Essas contribuições não invalidam os resultados dos trabalhos brasileiros que não se valem dessas fontes, mas oferecem complementos com vistas à expansão do estado da arte nacional a respeito do tema. Veremos que os autores pesquisados, embora não neguem as origens orais desses contos, apresentam-nos indícios de que a autoria dessas obras se distribui entre uma miríade de autores em um fenômeno complexo que Pabst (2014) denominou "autoria distribuída” ou "dispersa" (zerstreute Autorschaft). Além disso, em uma obra já conside- 
rada canônica em âmbito internacional e ainda pouco difundida no Brasil, Bottigheimer (2009) apresenta-nos a perspectiva de que a origem dos contos de fadas seria, em grande parte, literária.

Levando em conta essas perspectivas, procuramos pô-las em diálogo no item a seguir e oferecer algumas conclusões, a final, a respeito do leque de possibilidades que esses autores nos oferecem.

\section{Perspectivas em discussão}

Desde seu surgimento nos anos oitenta do século XX, o livro $O$ conto de fadas: símbolos, mitos, arquétipos, de Nelly Novaes Coelho (2003 [1986]), vem sendo utilizado como uma das obras mais extensas e detalhadas a respeito desse gênero literário disponível em nossas bibliotecas. O texto é, de fato, pioneiro em nosso país, assim como foi a atuação da professora e pesquisadora que criou a área de Literatura Infantil e Juvenil do Departamento de Letras Clássicas e Vernáculas da Universidade de São Paulo, alçando essa literatura à posição de relevância e importância que, de fato, lhe competem, em um caminho contrário ao de estudiosos das letras que, imbuídos pelo preconceito, preferiam ignorar essas obras como sendo fundamentalmente pedagógicas e de escasso interesse artístico - visão essa que, felizmente, vem se dissipando graças à atuação insistente e qualificada de estudiosos de literatura infantil e juvenil espalhados pelas universidades de nosso país. Como obra principal a ser consultada por pesquisadores do conto de fadas no Brasil, entretanto, esse livro já apresenta relevantes lacunas que requerem complementação em diálogo com a pesquisa internacional. Veremos, neste ínterim, o tratamento que a autora dá à questão das origens do conto de fadas.

Diferentemente do que afirmam alguns autores a serem tratados na sequência, Coelho (2003) aponta para a tradição oral e a "memória do povo" como fonte privilegiada dos contos dos Irmãos Grimm, a partir do que lhes contaram suas informantes Katherina Wieckmann e Jeanette Hassenpflug. A professora assevera que os Irmãos teriam eliminado, já na segunda edição da obra, os trechos de violência, sobretudo contra a criança, dada a crueldade intrínseca a vários dos contos “originais". Em terceiro lugar, menciona os contos de Andersen, por meio dos quais o autor falaria diretamente às crianças, em histórias marcadas por ideais românticos. 
Como fontes arcaicas dos contos de fadas, a autora lista origens egípcias (papiro contendo o conto Os dois irmãos, entre outros) e orientais (por exemplo, a narrativa indiana Calila e Dimna e a coletânea Sendebar), bem como As mil e uma noites. Em seguida, sugere fontes céltico-bretãs para essas narrativas maravilhosas, incluído o romance cortês. Indica, ainda, como fontes os contos maravilhosos populares medievais. Sobre Chapeuzinho Vermelho, escreve:

Chapeuzinho Vermelho é de origem incerta. O tema é antiquíssimo e aparece em vários folclores. Sua célula originária estaria no mito grego de Cronos, que engole os filhos, os quais, de modo miraculoso, conseguem sair de seu estômago e o encher de pedras. Exatamente o final escolhido pelos Irmãos Grimm. Tal tema é encontrado ainda em uma fábula latina do século XI, Fecunda ratis, que conta a estória de uma menina com um capuz vermelho, devorada por lobos, escapando milagrosamente e enchendo-lhe a barriga com pedras (COELHO, 2003, p. 39).

Percebe-se, neste trecho citado, que a autora reconhece o fato de os Grimm terem "escolhido" um final para o conto, o que atesta o fato também apontado por outros autores que serão abordados neste trabalho de que os contos de fadas literários possuem alterações e estilizações pelas quais são responsáveis os autores das coletâneas (por alguns denominados “coligidores”), deste modo não representando fielmente as supostas fontes orais da tradição popular. É notório, também, que Coelho indica essa tradição oral popular como origem dos contos, mas, simultaneamente, assinala como gênese dessas narrativas obras literárias que lhes antecederam, à semelhança do que propõe Bottigheimer (2009), autora a ser discutida na sequência. O livro de Coelho não explica, entretanto, em que medida as fontes orais e literárias deram origem aos contos de Perrault e Grimm e qual seria a participação de cada um dos dois tipos de fontes na constituição dos contos "originais" que vieram a ser retrabalhados literariamente pelos autores das coletâneas.

Segundo Zipes (1994), os contos de fadas literários teriam surgido nos salões da aristocracia do século XVII, onde teriam sido narrados por mulheres, na forma de uma espécie de jogo de salão. Esses jogos serviriam para que as mulheres demonstrassem sua inteligência e educação e teriam dado origem a textos literários de gêneros como a novela e as letras de música, em momentos de divertimento: "A narração de contos de fadas permitiu às mulhe- 
res representar a si mesmas, costumes sociais e relações de um modo que representasse seus interesses e aqueles da aristocracia" (ZIPES, 1994, p. 21)4. Era importante que parecesse que os contos tinham sido inventados naquele momento, de forma improvisada; em certos casos, era solicitado à narradora que contasse um conto sobre certo motivo que lhe era proposto na hora; sua habilidade de improvisar era, então, bastante valorada. Assim, por volta de 1690, era solicitado aos narradores dos salões que escrevessem os contos que haviam contado nos jogos, contexto que deu origem, entre outros, aos contos literários de Charles Perrault. Esses contos, originalmente narrados nos jogos dos salões, não teriam sido, incialmente, pensados para crianças, diferentemente do que ocorre com os contos de Grimm, que foram adaptados para que fossem apropriados para serem lidos por infantes. Todavia, as crianças já eram, nesses tempos, receptores dos contos, que ouviam da boca de suas governantas, serviçais e outras crianças. Com o tempo, os contos foram adaptados para incluir lições de moral destinadas ao público infantil das classes mais abastadas. Esses contos destinados às crianças teriam surgido entre 1720 e 1730 .

A partir desses dados, percebe-se que Zipes nos oferece informações diferenciadas sobre as origens do conto de fadas literário, sobretudo o francês do século XVIII. Essas informações confirmam uma origem a princípio oral dessas narrativas, que teriam sido contadas nos salões da aristocracia e posteriormente fixadas de forma escrita. Este contexto nos leva a visitar o livro de Ruth Bottigheimer, que nos apresenta outra perspectiva acerca da origem desse gênero.

Bottigheimer (2009), em texto bastante explorado na pesquisa anglo-saxã sobre esta temática, dedica-se à história dos contos de fadas, propondo-se a traçar-lhes "uma nova história", uma "história reversa" que se inicia com os contos de Grimm e avança rumo ao passado em busca das origens dessas narrativas. Na visão desta autora, tem-se como subentendido e amplamente aceito que a origem dos contos de fadas se assenta na tradição oral, com os contos sendo transmitidos de boca em boca e através dos tempos e territórios, principalmente por camponeses, bem como nos antigos mitos (assim como afirmam Zipes,

4 Trecho original: "The telling of fairy tales enabled women to picture themselves, social manners, and relations in a manner that represented their interests and those of the aristocracy". Todas as traduções encontradas no corpo do texto são de nossa autoria. 
1994 e Volobuef, 2011). Entretanto, ela assevera que essa visão dista de ser um fato verificável e sustentado por evidências.

A pesquisadora inicia sua argumentação sublinhando as diferenças existentes entre o conto de fadas ("fairy tale"), o conto de magia ("tale of magic") e o conto popular ("folk tale"), e discordando daqueles que tomam esses termos como sinônimos. Segundo afirma, o conto popular diferiria do conto de fadas em sua estrutura, personagens, enredo e idade. Ele seria breve, com enredo linear, "refletindo o mundo e o sistema de crenças de seu público"s. Seria povoado por maridos e esposas, andarilhos, e eventualmente um médico, advogado ou pastor, tematizando também as dificuldades de um matrimônio. No enredo desses contos, uma pessoa frequentemente toma o dinheiro, os bens ou fere a honra de outra, e a maioria deles não possui um final feliz (BOTTIGHEIMER, 2009).

O conto de magia, por sua vez, necessariamente apresenta elementos mágicos, mas estes também constam de contos de fadas, lendas, contos religiosos e anedotas. A autora menciona exemplos de enredos de contos de magia, mas não tece comentários mais específicos de modo a definir precisamente quais seriam as características desses contos e o que os diferiria dos demais gêneros nos quais a magia consiste em elemento fundamental.

Sobre os contos de fadas, a autora menciona os "contos de fadas populares" ("folk fairy tales"), aqueles que teriam sido supostamente transmitidos de forma oral durante séculos entre a população e que a posteriori vieram a ser fixados de forma escrita a partir do trabalho de diferentes autores que os teriam coletado junto ao povo, em um gesto de apropriação que dá origem ao conto de fadas literário ("literary fairy tale"), em oposição ao conto de fadas "original”, tradicionalmente encarado como sendo de origem oral. Autores que realizaram esse trabalho de apropriação seriam, entre outros, Giovan Straparola, Giambattista Basile, Marie-Catherine d'Aulnoy, Charles Perrault e os Irmãos Grimm. Sobre estes últimos, Bottigheimer nos lembra que existe a crença - errônea - de que eles haveriam preservado os contos populares em sua essência, embora, em realidade, tenham procedido a várias alterações e estilizações desses contos, assim como também afirma Volobuef (2011). Entre outras alterações, Wilhelm teria lhes incutido seu aspecto infantil e associado à infância do mundo.

5 Trecho original: "(...) folk tales reflect the world and the belief systems of their audiences". 
Bottigheimer afirma que o termo "conto de fadas" está envolvido em uma nebulosa de confusões originadas pelo título em inglês dos Contos maravilhosos infantis e domésticos: "Grimm's fairy tales". Como observa a autora, as fadas estão ausentes no título original alemão e nos contos coletados nessa obra, entre eles contos de advertência (como Chapeuzinho Vermelho), de origem, de animais e populares. A autora cita Zipes, segundo quem transformações milagrosas, finais felizes, personagens de repertório e determinados motivos constituiriam elementos que compõem o conto maravilhoso "oral" (aspas da autora), que, uma vez escritos, teriam originado o gênero dos contos de fadas literários ("literary fairy tales").

Bottigheimer não apenas põe em dúvida a origem supostamente oral dos contos de fadas populares, como também coloca em disputa a tendência generalizada de se definir esses contos pelos motivos e estruturas que neles aparecem. Assim, afirma que

$$
\begin{aligned}
& \text { motivos próprios dos contos de fadas tais como anéis mágicos e o número três } \\
& \text { aparecem em romances italianos dos séculos XV e XVI; a estrutura dos contos de } \\
& \text { fadas, assim como postulada por Propp ou outros, subjaz a numerosas novelas; e os } \\
& \text { finais felizes de contos de fadas definem romances de sexo e violência dos séculos } \\
& \text { XIX, XX e XXI. Portanto, não são os motivos, estrutura ou os finais felizes que de- } \\
& \text { finem os contos de fadas, mas sim a trajetória geral do roteiro de contos individuais } \\
& \text { em conjunção com aqueles elementos desses contos conjugados em uma narrativa } \\
& \text { compacta (BOTTIGHEIMER, 2009, p. 9). }{ }^{6}
\end{aligned}
$$

A autora considera que a extensão da narrativa, diferentemente dos itens citados acima, que também fazem parte há séculos dos romances, é um aspecto central para a definição dos contos de fadas, diferenciando-os dessas outras obras. Ao pôr em dúvida a noção amplamente aceita de que a totalidade dos contos teria sido elaborada e transmitida oralmente por pobres e

6 Trecho original: "Fairy tale motifs such as magic rings and the number three appear in fifteenth-and sixteenth-century Italian romances; fairy tale structure, Proppian or otherwise, underlies a great any novels; and fairy tale bappy endings define nineteenth-, twentieth-, and twenty-first-century bodice-ripping romances. Thus it is not motifs, structure, or happy endings alone that define fairy tales, but the overall plot trajectory of individual tales in conjunction with those fairy tale elements all brought together within a "compact" narrative (...)". 
analfabetos camponeses, ela propõe, em vez disso, uma natureza urbana (imaginário, personagens e referências) para os contos mais antigos. Épocas em que grande parte da população era bastante pobre e a concorrência de produtos mais baratos produzidos no exterior gerava desemprego, no norte da Itália, ofereciam um contexto propício para o surgimento de contos como os de ascensão: "é a intersecção de uma impossibilidade na vida real e seu alcance na fantasia que marca o nascimento do conto de fadas de ascensão moderno" (BOTTIGHEIMER, 2009, p. 21). ${ }^{7}$ A autora afirma que a origem dos contos de restauração corresponde aos romances que lhes precederam, e que "roteiros precursores sobre a restauração dos deslocados e figuras reais sofredoras que retornaram à sua posição de direito são aproximadamente tão antigos quanto o contar histórias, assim como o são os motivos que caracterizam tais contos” (p. 24). ${ }^{8}$

Sobre os contos de Grimm, a pesquisadora retoma a origem comumente difundida dessas narrativas: boa parte delas, incluída Chapeuzinho Vermelho, teria sido contada aos irmãos por jovens garotas da região de Kassel, na Alemanha: entre elas, Dörtchen e Gretchen Hassenpflug, membros da classe social mais abastada. Além delas, Friederike Mannel e Charlotte lhes narraram outros contos que foram incluídos no primeiro volume, e lhes apresentaram Dorothea Viehmann, de origem mais humilde, que trouxe importantes contribuições para o segundo tomo. Esse volume continha, ainda, contribuições de outras jovens informantes. Assim, Bottigheimer põe em disputa a origem supostamente popular da totalidade dos contos: enquanto Viehmann poderia ser vista como uma informante que realmente fazia parte do povo, o mesmo não poderia ser dito das irmãs Hassenpflug, membros de uma elite econômica urbana. Por esse motivo, muitos historiadores acreditam que os contos teriam sido contados às ricas meninas por seus empregados, esses sim de fato membros do povo; entretanto, não existem registros dos nomes ou identidades desses serviçais. Com linha de raciocínio semelhante, Darnton (1986) afirma que

7 Trecho original: "It is the intersection of a specific impossibility in real life and its achievement in fantasy that marks the birth of the modern rise fairy tale".

8 Trecho original: "Precursor plots about the restoration of displaced and suffering royal figures who returned to their rightful position are nearly as old as storytelling itself, as are many of the motifs that characterize restoration fairy tales". 
os contos que chegaram aos Grimm através dos Hassenpflug não eram nem muito alemães nem muito representativos da tradição popular. Na verdade, os Grimm reconheceram sua natureza literária e afrancesada e, por isso, eliminaram-na da segunda edição do Kinder- und Hausmärchen — com exceção de "Chapeuzinho Vermelho". Este permaneceu na coletânea, evidentemente, porque Jeannette Hassenpflug lhe enxertara um final feliz, tirado de "O lobo e as crianças" (conto do tipo 123, de acordo com o esquema de classificação padrão elaborado por Antti Aame e Stith Thompson), um dos mais populares na Alemanha. Assim, "Chapeuzinho Vermelho" inseriu-se na tradição literária alemã e, mais tarde, na inglesa, com suas origens francesas não detectadas. Ela mudou consideravelmente suas características, ao passar da classe camponesa francesa para o quarto do filho de Perrault e daí partir para a publicação, atravessando depois o Reno e voltando para uma tradição oral, mas, desta vez, como parte da diáspora huguenote, dentro da qual retomou sob a forma de livro mas, agora, corno produto da floresta teutônica, em lugar das lareiras das aldeias do tempo do Antigo Regime, na França (DARNTON, 1986, p. 24). ${ }^{9}$

Bottigheimer ressalta que, para Wilhelm Grimm, os contos de fadas seriam parte da natureza, bem como resquícios de antigas formas poéticas alemãs, supostamente não modificadas ao longo do tempo e fielmente reproduzidas, de forma oral, entre camponeses e cidadãos do povo, algo que corroboraria um desejo de unificação cultural (e também política) dos diferentes povos alemães, entre os quais teriam circulado, sem modificações, essas narrativas: "Wilhelm escreveu, e acreditava, que os contos não apenas abarcavam a alemanidade, mas também que eles mostravam aos alemães como ser alemães" (BOTTIGHEIMER, 2009, p. 38) ${ }^{10}$. Apesar disso, a autora sustenta que os contos de fadas alemães derivariam dos de tradição francesa e estes, dos de origem italiana. Ele localizou em países como Dinamarca, Noruega,

9 "O lobo e as crianças" é outra tradução difundida no português de "O lobo e os sete cabritinhos" ("Der Wolf und die sieben Geisslein").

10 Trecho original: "Wilhelm wrote, and believes, that the tales not only embodied German-ness, but that they showed Germans how to be German". 
Suécia, Inglaterra, País de Gales, França, Espanha e Itália contos semelhantes aos que estava coletando na Alemanha e, segundo Bottigheimer, esses contos, parecidos entre si, vieram de livros publicados. Assim, a autora propõe uma origem majoritariamente literária para os contos de fadas coletados pelos Grimm.

$\mathrm{Na}$ visão de Bottigheimer, os Irmãos Grimm desconheciam a realidade do povo ao qual atribuíam a autoria dos contos que coletaram, uma vez que faziam parte de um estrato mais privilegiado da sociedade, tendo uma visão ingênua dessa população que trataram de transpor aos contos de sua coletânea. A autora afirma que os contos do primeiro volume da compilação teriam origem literária, ao menos parcialmente. Esta é a sua tese, que denomina "nova história" dos contos de fadas e dos contos de Grimm em particular:

\footnotetext{
No final dos anos 1980 e no início dos anos 1990, graças a novas catalogações realizadas eletronicamente, acadêmicos puderam verificar transferências intertextuais de livros para informantes orais em um crescente número de casos, e os resultados revelaram que os contos do volume 1 - longe de terem se originado junto ao povo iletrado - demonstraram profundas conexões entre histórias contadas a Jacob e Wilhelm por suas jovens amigas de Kassel, por um lado, e contos de fadas europeus publicados, de outro (BOTTIGHEIMER, 2009, p. 49-50). ${ }^{11}$
}

As evidências para essa asserção seriam motivos e enredos contidos nos contos de Grimm que seriam muito semelhantes àqueles encontrados em contos de fadas europeus preexistentes. Essas histórias teriam, por sua vez, sido lidas pelas irmãs de Kassel que atuaram como informantes dos Grimm, bem como por outras jovens mulheres no final do século XVIII e início do século XIX. Essa conclusão é tomada porque as histórias que pré-dataram e influenciaram os contos de Grimm já haviam sido publicadas em livros, de origem francesa

11 Trecho original: "By the late I980s and early I99os, thanks to re-cataloguings carried out electronically, scholars could verify intertextual carryovers from books to oral informants in an increasing number of cases, and the results steadily revealed that the fairy tales of Volume I - far from originating among an illiterate folk - demonstrated close connections between stories told to Jacob and Wilbelm by their Young Cassel friends on the one hand and published European fairy tales on the other". 
e alemã, lidos por esse público há ao menos cinquenta anos antes da coleta das narrativas. Os irmãos não teriam, todavia, sabido desse fato, uma vez que foram criados em um lar no qual não penetrava a "literatura frívola". Sendo grande parte dos contos originária da literatura francesa, a crença dos Grimm na alemanidade teria sido, no mínimo, ingênua: "A França proveu a Alemanha com sua tradição de contos de fadas" (BOTTIGHEIMER, 2009, p. 75) ${ }^{12}$ Assim, a autora considera inválida a visão tradicional dos historiadores e as declarações dos Grimm a respeito da origem supostamente oral dos contos, acreditando, pelo contrário, que essas narrativas teriam sua gênese em obras publicadas na França e na Alemanha antes da coleta por parte dos irmãos, tendo sido lidas pelas informantes que lhes narraram essas histórias. A linha de raciocínio de Bottigheimer se sustenta a partir de uma interpretação peculiar de dados históricos disponíveis sobre essa época e seu contexto, e contém uma série de suposições (por exemplo, que as irmãs Hassenpflug teriam lido os livros de contos anteriores à coleta, uma vez que eram letradas, pertenciam a um lar abastado e aberto à "literatura trivial" e faziam parte do grupo demográfico que consumia esse tipo de livro). Deste modo, não se baseia em documentos que provem de forma explícita e indiscutível ser realmente literária a origem dos contos. Por não apresentar evidências documentais daquilo que afirma, e por elaborar seus argumentos com base em possibilidades e conjecturas, pode-se dizer que o que Bottigheimer nos apresenta é uma hipótese talvez inverificável acerca da suposta origem não oral dos contos de fadas - mas uma hipótese que também faz sentido e, se não explica de forma crível a origem da totalidade dos contos de fadas, aponta uma possibilidade concreta de origem de certa parte deles. Por tratar-se de apenas uma hipótese explicativa, sem evidências documentais, não há como invalidar outras hipóteses aqui apresentadas, como a de Coelho, por exemplo, além das de outros pesquisadores. Ademais, cada leitura explicativa sustenta-se em um prisma epistemológico, teórico, metodológico, de forma que a hipótese apresentada é validada a partir desse construto, não se revelando como "a verdade" mais atualizada sobre o fenômeno. Apesar disso, a hipótese de Bottigheimer nos instiga à reflexão e nos oferece dados complementares que nos permitem circunscrever com maiores detalhes a nebulosa questão das origens e da autoria dos contos de fadas.

12 Trecho original: "France provided Germany with its fairy tale tradition". 
Uma informação que potencialmente corrobora a tese de Bottigheimer é aquela que nos oferece Martus (2009, p. 203-4) em um trabalho biográfico sobre os Irmãos Grimm. O autor afirma que, à época da publicação da primeira edição dos Kinder- und Hausmärchen, o mercado editorial alemão já havia assistido ao surgimento de diversas coleções de contos de fadas (Märchensammlungen) de outros autores, o que, segundo ele, indicaria também um interesse do público dessa era nesse tipo de obra. Entre os trabalhos dessa sorte que antecederam os Grimm, encontram-se a série Volksmärchen der Deutschen (“Contos populares dos alemães”), de Johann August Musäus, de 1782, bem como os Kindermärchen aus mündlichen Erzählungen gesammelt ("Contos infantis coletados de narrações orais"), de Wilhelm Günther (1787). Além delas, foram publicadas: Neue Volksmärchen der Deutschen ("Novos contos populares dos alemães"), de Benedikte Naubert (1798-1993) e as coletâneas anônimas Annenmärchen, de 1792/92, Märleinbuch für meine lieben Nachbarsleute (“Contos de fadas para meus caros vizinhos”), de 1799, e Feen-Märchen (“Contos de fadas”), de 1801. Albert Ludwig Grimm, um escritor coincidentemente de mesmo sobrenome que os irmãos de Kassel, publicou em 1808 seus Kindermärchen (“Contos infantis”), e Johann Gustav Büsching, em 1812, poucos meses antes da publicação da coletânea dos Grimm, apresentou seus Märchen und Legenden (“Contos de fadas e legendas"). Nenhuma dessas obras gozou da fama e reconhecimento dos Kinder- und Hausmärchen, que, de acordo com Martus (2009, p. 204), seria o livro alemão mais conhecido no mundo depois da Bíblia de Lutero. Entretanto, sabendo-se o quão estudiosos eram os Irmãos Grimm, não seria exagerado supor que tivessem conhecimento de ao menos parte dessas coletâneas publicadas antes da sua, e que esse conhecimento pudesse ter exercido algum tipo de influência na composição de sua própria obra. Se isso efetivamente ocorreu e de que forma, não é possível comprovar com base nas fontes consultadas para este trabalho. O que se pretende, com essa sugestão, é indicar que, na esteira do que nos propõe Bottigheimer, existem evidências de que a obra de Grimm possui, além das fontes orais comumente atribuídas aos contos de fadas, traços indicativos de uma origem também literária. Como afirma o próprio Martus (2009, p. 210), “materiais advindos de fontes burguesas, femininas e com formação literária confluíram abundantemente nos Contos maravilhosos infantis e domésticos, ao passo que a 
pesquisa diretamente junto aos locais e pessoas, onde, segundo a teoria, o 'bem popular' deveria poder ser encontrado, mostrou-se difícil"13.

A discussão sobre a autoria dos contos de fadas também foi expandida por Pabst (2014). O autor (PABST, 2014, p. 136-7) inicia seu ensaio recordando-nos de que, na primeira edição dos Kinder- und Hausmärchen, o nome dos Irmãos Grimm não surge como se esses fossem, de fato, os autores da obra, mas sim seus coletores ou compiladores (Sammler, termo eventualmente também traduzido como "coligidores"). Isso porque os próprios Grimm entendiam que os contos de fadas reunidos nesse volume não seriam fruto - ao menos não exclusivamente - de uma autoria e intencionalidade individuais, sendo produto de uma concepção coletiva popular alemã, o que seria próprio do que denominam Volkspoesie ("poesia do povo/popular"). A princípio, tendo sido coletados em Hesse, os contos de Grimm corresponderiam a uma tradição folclórica germânica, mas semelhanças entre essas narrativas e outras de origens diversas indicam uma mistura de tradições culturais e linguísticas que lhes deram origem.

Isso levanta a seguinte questão: os contos compilados pelos Grimm seriam, por isso, de autoria anônima? Existem casos, como o conto Rapunzel (o décimo segundo da coletânea), cuja autoria, embora afirmassem os Grimm tratar-se de narrativa advinda da tradição oral, é associada a autores como Friedrich Schulz (Kleine Romane), a partir de um conto de Charlotte-Rose Caumont de La Force que, por sua vez, retrabalhava a obra Pentamerone de Basile. No caso de Rotkäppchen (Chapeuzinho Vermelho), é sabido que o texto teve, como base, a versão de Perrault, mas os Grimm citavam, como fonte primeva da narrativa, a região do Meno, onde o conto haveria sido coletado por Jeanette Hassenpflug. Assim, Pabst (2014, p. 141) afirma que "os Grimm ocultam sistematicamente a autoria através da instância do narrador ou, com mais frequência, da narradora"14. O autor também afirma (p. 142) que os Grimm procediam a um deslocamento da figura do autor por meio daquela do narrador(a). Com isso, o autor se

13 Trecho original: "Materialien aus bürgerlichen, weiblichen, literarisch gebildeten Quellen flossen den Kinder- und Hausmärchen reichlich zu, während sich die Recherche gerade an den Orten und bei den Personen, wo das ,Volksgut' der Theorie nach bätte zu finden sein sollen, als schwierig erwies".

14 Trecho original: "Überdies verdecken die Grimms Autorschaft systematisch durch die Instanz des Erzählers, öfter noch der Erzählerin". 
refere às informantes dos irmãos, como Hassenpflug e Dorothea Viehmann, a quem se atribui o papel de fontes dos Grimm. Essa última, embora a ela se referissem os Grimm como sendo tipicamente de Hesse, seria, de fato, de origem francesa, algo perceptível nos contos narrados por ela, bastante semelhantes àqueles que circulavam pelo país vizinho.

Pabst nos fala, assim, de um espalhamento, dispersão ou distribuição (Zerstreuung) da autoria. Nesse sentido, afirma (2014, p. 142): “A ficção da oralidade, que os Grimm consistentemente sustentam, leva, como consequência, a um espalhamento da autoria"15. Isso se deveria a uma estratégia: ao relegar-se ao narrador a autoria da obra, o que se escrevesse permaneceria sem ser contestado, mesmo após seu falecimento. Na concepção de autoria favorecida pelos Grimm, o conceito de narrador se sobreporia ao de autor, que permaneceria obscurecido. Apesar disso, os contos, assim como registrados pelos irmãos, apresentam diversas alterações e estilizações (em uma reconstrução), que são de sua responsabilidade, não correspondentes, portanto, a um fiel registro de elementos da tradição popular. Uma imprecisão no reconhecimento dos autores de cada tipo de contribuição que deram origem à obra, nesse contexto de dispersão da autoria, leva também a uma anonimidade, ou mesmo à negação de uma autoria para os textos no sentido em que comumente entendemos esse termo.

O conceito de dispersão da autoria cunhado por Pabst e aplicado à situação dos Kinderund Hausmärchen (Contos maravilhosos infantis e domésticos) define de forma precisa o que de fato ocorre no contexto dos contos de fadas literários. Sua origem é, ao menos parcialmente, oral e tradicional, uma vez que se entende que esses contos circularam por séculos na boca do povo e espalhados por diversos territórios, ao longo dos séculos; ao mesmo tempo, as informantes dos Grimm também estavam influenciadas pela leitura de outros contos de fadas literários, como afirma Bottigheimer, e podem ter acrescentado, ao narrar-lhes as histórias, elementos de sua autoria; por fim, os próprios Grimm realizaram diversas modificações nas histórias, adaptando-as ao gosto infantil, extraindo-lhes elementos escatológicos, dotando-lhes de certo estilo. Por esse motivo, é possível afirmar que a autoria dos contos de Grimm é dispersa, imprecisa, distribuída e, em certa parte, anonimizada.

15 Trecho original: "Die Fiktion der Mündlichkeit, die die Grimms konsequenz aufrechterbalten, dient mithin nicht minder dazu, Autorschaft zu zerstreuen". 
As perspectivas ora apresentadas também apresentam seus poréns. Trataremos, a seguir, de assinalar alguns desses senões e propor caminhos de investigação para o aprofundamento da pesquisa sobre o tema.

\section{Conclusões}

Os autores pesquisados mostram-nos que a questão da autoria dos contos de fadas é bastante complexa e ainda merece ser estudada com maior profundidade. Observa-se, recentemente, uma profusão de livros (ilustrados ou não) de contos de fadas que se propõem apresentar-nos a "versão verdadeira" desses relatos, como vemos em Almodóvar e Taeger (2008), que retomam versão de Chapeuzinho Vermelho discutida em Darnton (1986). A busca de uma hipotética versão "verdadeira" dos contos visa a localizar narrativas supostamente não modificadas pela pena de escritores, mas a natureza dos registros de que dispomos dessas versões dos contos não nos permite atestar a origem exclusivamente folclórica de nenhuma delas.

Percebemos, à guisa de exemplo, que o trabalho mais disseminado entre aqueles aqui discutidos, o de Bottigheimer (2009), baseia-se em conjecturas lógicas que a autora não trata de comprovar com uma análise comparativa de textos. Uma vez que a autora afirma serem encontráveis em romances italianos motivos e elementos considerados pelo senso comum representantes da oralidade que supostamente ter-lhes-ia dado origem, ela abre mão de citar nominalmente algumas dessas obras e de demonstrar, como se espera em um trabalho científico sobre a literatura, os fatos a partir da análise textual - no caso, comparativa. Ignora, também, o fato de que alguns desses motivos já estavam presentes nas narrativas bíblicas, e investigar sua transposição e presença na estrutura do conto de fadas também é um caminho de pesquisa pouco ou não explorado que requer investigações mais detidas.

Essencialmente, procuramos, com este escrito, trazer à luz, de forma não pretensamente exaustiva, os pensamentos de alguns autores estrangeiros a respeito da temática da autoria e da origem dos contos de fadas que vêm sendo ignorados na pesquisa brasileira, possivelmente pela dificuldade imposta pela ausência de traduções publicadas dessas obras, 
bem como pelo ainda exíguo diálogo entre pesquisadores e grupos de pesquisa brasileiros e anglo-saxões dedicados ao tema.

Urge, portanto, que a pesquisa brasileira sobre o conto de fadas conecte-se àquelas realizadas em outros países, como Alemanha, Inglaterra e Estados Unidos, onde a tradição de estudos desse assunto é solidamente assentada, sendo necessário penetrar o meio universitário brasileiro de forma mais contundente. 


\section{Referências}

ALMEIDA, T. (Org.). Relacionamentos amorosos: o antes, o durante... e o depois deles. São Carlos: Compacta, 2013.

ALMODÓVAR, A.R.; TAEGER, M. Chapeuzinho Vermelho: a verdadeira bistória. São Paulo: Callis, 2008.

BETTELHEIM, B. A psicanálise dos contos de fadas. São Paulo:Paz e Terra, 1980.

BOTTIGHEIMER, R. Fairy tales: a new story. Nova York, Excelsior, 2009.

COELHO, N. N. O conto de fadas: símbolos, mitos, arquétipos. São Paulo: DCL, 2003.

DAMASCENO, E. Para além dos contos de fadas: o ideal e o real no pensamento das mulheres sobre o casamento. Dissertação (Mestrado em Psicologia). Assis: UNESP, 2008.

DARNTON, R. O grande massacre dos gatos. São Paulo: Graal, 1986.

MARTUS, S. Die Brüder Grimm: eine Biographie. Berlim: Rowohlt, 2009.

PABST, S. Zerstreute Autorschaft: Anonymität als Autorisierungsfunktion Grimmscher Märchen. Fabula, 55 (1/2), 2014, p. 135-152.

SCHNEIDER, R.; TOROSSIAN, S. Contos de fadas: de sua origem à clínica contemporânea. Psicologia em Revista, v. 15, n. 2, p. 132-148, ago. 2009. 
VOLOBUEF, K. Os Irmãos Grimm e as raízes míticas dos contos de fadas. In: VOLOBUEF, K.; ALVAREZ, R. G. H.; WIMMER, N. (Orgs.). Dimensões do fantástico, mítico e maravilhoso. São Paulo: Cultura Acadêmica, 2011, p. 47-61.

ZIPES, J. Fairy tale as myth, myth as fairy tale. Lexington: University Press of Kentucky, 1994. 